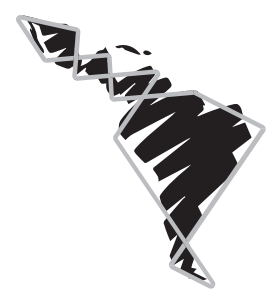

\title{
50 años de la Reforma Agraria chilena. De la protección a la vulneración de los derechos campesinos
}

\author{
Fifty Years of the Chilean Agrarian \\ Reform: From the Protection to the \\ Violation of Peasants' Rights
}

\section{0 anos da Reforma Agrária chilena. Da proteção a vulnerabilidade dos direitos dos camponeses}

\author{
Patricia Castañeda Meneses ${ }^{1}$
}

\begin{abstract}
Resumen
El presente artículo se inscribe en el marco de la conmemoración de los 50 años de la Reforma Agraria chilena y tiene por objetivo analizar los procesos de Reforma Agraria y Contrarreforma Agraria, desde la perspectiva de la protección de los derechos campesinos. Estos derechos correspondían a acceso a la tierra, acceso a la asistencia técnica, acceso al crédito agrícola preferente, acceso a la comercialización, derecho de asociación sindical de los trabajadores agrícolas, e incluían los derechos sociales de educación, salud y vivienda. Su cumplimiento fue asumido por los organismos estatales y concretizado en una reforma constitucional y cuerpos legales que formalizaron el proceso y le dieron viabilidad como política del Estado. Se crearon organismos públicos definidos para apoyar la labor de redistribución de la propiedad agraria, se contó con recursos públicos declarados en el presupuesto nacional y con acciones intersectoriales destinadas a este importante grupo social. A partir del golpe de Estado de 1973 se inicia un proceso de Contrarreforma Agraria que vulneró progresivamente los derechos campesinos. La tierra fue entregada en forma individual, sin asistencia técnica estatal ni acceso preferente al crédito agrícola y se abandonaron las acciones destinadas a garantizar derechos sociales. Como resultado, se estima que más del $50 \%$ de las tierras asignadas a campesinos fueron vendidas, creando un mercado agrario de tierras y de mano de obra rural que es la base del actual capitalismo chileno agroexportador.
\end{abstract}

1 Trabajadora Social, Doctora en Ciencias de la Educación. Académica e Investigadora. Escuela Trabajo Social, Universidad de Valparaíso, Chile. 
Palabras clave: propiedad de la tierra, reforma Agraria, contrarreforma Agraria, derechos campesinos.

\begin{abstract}
This article was written on the occasion of the 50-year commemoration of the Chilean agrarian reform. It aims to analyze the processes of agrarian reform and counter-reform, from the perspective of the protection of peasants' rights. These rights related to access to land, technical assistance, agricultural preferential credit, and marketing, as well as the right of association of agricultural workers. They included the social rights to education, health and housing. Compliance with these rights was assumed by state agencies and materialized in a constitutional reform and in legal bodies that formalized the process and gave it viability as a state policy. Public agencies were created to support the redistribution of land ownership, public resources were assigned from the national budget, and intersectoral actions were taken in favor of this important social group. Ever since the coup d'état of 1973, a process of agrarian counter-reform started, and progressively violated the peasants' rights. The land was given out on an individual basis, without technical state support or preferential access to agricultural credit, and the actions aiming at ensuring social rights were abandoned. As a result, it is estimated that more than $50 \%$ of the allocated land to peasants was sold, creating a market of agricultural land and rural labor that is the base of the current Chilean agro-exporting capitalism.
\end{abstract}

Keywords: land ownership, agrarian reform, agrarian counter-reform, peasants' rights.

\title{
Resumo
}

Este artigo faz parte da comemoração do 50 aniversário da Reforma Agrária chilena e tem como objetivo analisar os processos de reforma e contra reforma agraria, a partir da perspectiva da proteção dos direitos dos camponeses. Esses direitos correspondiam ao acesso à terra, acesso a assistência técnica, acesso preferencial ao crédito agrícola, acesso ao comercio dos produtos, a liberdade de associação sindical dos trabalhadores agrícolas, e incluíam os direitos sociais de educação, saúde e moradia. As organizações federais assumiram a conformidade e a concretização numa reforma constitucional, através dos órgãos legais que formalizaram o processo e deram viabilidade como uma política de Estado. Foram criados organismos públicos definidos, com o fim de apoiar o trabalho de redistribuição das terras, contando com recursos públicos declarados no orçamento nacional e com ações intersetoriais destinadas a esse importante grupo social. Depois do golpe de Estado de 1973, teve inicio a um processo de contra reforma agrária que, gradualmente, vulnerabilizou os direitos dos agricultores. A terra foi dada individualmente, sem assistência técnica federal nem acesso preferencial ao crédito agrícola, e foram abandonadas as medidas para garantir os direitos sociais. Como resultado, estima-se que mais de 50\% das terras distribuídas aos agricultores foram vendidas, criando um mercado de terras agrícolas e de mão de obra rural, que é a base do atual capitalismo chileno agroexportador.

Palavras-chave: propriedade da terra reforma e contra reforma agrária, direitos dos camponeses. 


\section{Antecedentes generales}

El año 1967 se dictó la Ley de Reforma Agraria № 16.640, que en los hechos constituyó el marco legal que condujo efectivamente el proceso reformista en el agro chileno. En el marco de la conmemoración de los 50 años de la dictación del cuerpo legal, el presente trabajo tiene por objetivo analizar los procesos de Reforma Agraria y Contrarreforma Agraria chilenas, desde la perspectiva de los derechos campesinos. Para ese fin se ha revisado la información agraria y social histórica actualmente disponible, que ha permitido caracterizar los procesos reformista y contrarreformista en sus principales eventos y examinar las implicancias y consecuencias que estos tuvieron en la definición, ejercicio y protección de los derechos de la población campesina, analizados en el marco del proceso estructural de transformación agraria sucedido en el país.

El punto de partida del proceso reformista es el reconocimiento a la existencia de una estructura histórica de la propiedad agraria chilena, arraigada desde tiempos coloniales, que se caracterizaba por constituir un concentrado complejo latifundio/minifundio, donde los grandes propietarios agrarios manejaban el $72,7 \%$ de la tierra arable del país, mientras que los pequeños propietarios poseían el 1,4\% del recurso (Alaluf, Robles y López, 1969, p. 98). Según los datos arrojados por el Censo Agropecuario del año 1965, existían 730 explotaciones de una extensión superior a las 5.000 hectáreas, que concentraban casi el $50 \%$ de las tierras agrícolas del país, mientras que 45.233 propiedades eran menores a una hectárea (Bengoa, 1984, p. 26). La producción agropecuaria estaba destinada en casi su totalidad al mercado interno y su posición económica era subordinada al crecimiento industrial (Suárez, 1972, p. 47).

El sistema de mano de obra rural predominante en las grandes haciendas correspondía al inquilinaje, sistema formado por campesinos sin tierras que vivían en el interior del predio y cuyo sistema de retribución por su trabajo agrícola correspondía a regalías de tierra y de talaje de animales para el consumo doméstico y en situaciones de excepción, dinero en efectivo en una mínima proporción (Rivera, 1988, p. 69). Por lo general, sus condiciones materiales de vida eran precarias y sus garantías laborales inexistentes. En atención a su prolongada extensión en el tiempo, el inquilinaje originó una cultura rural feudal de alta dependencia y obediencia del campesinado a las decisiones de los hacendados (Bengoa, 1984, pp. 27-28). Esta situación era fuertemente criticada desde inicios del siglo XX y se buscaban propuestas de cambio que reconocieran el derecho campesino de organización sindical y el derecho de quienes trabajan la tierra a poseerla. En ese marco, se plantean como primeras iniciativas la creación de la Caja de Colonización Agrícola en el año 1929, organismo encargado de formar, dirigir y administrar 
colonias destinadas a organizar e intensificar la producción agrícola a partir de la parcelación de grandes haciendas; y la dictación de la primera Ley de Sindicalización Campesina en el año 1943, que se constituyó en uno de los primeros referentes legislativos que reconoció el derecho a la organización campesina, aunque en los hechos prácticamente no fue aplicada (Ortega, 1987, p. 31).

Dos décadas más tarde, surgió la Alianza para el Progreso - pacto de cooperación impulsado desde Estados Unidos hacia los países latinoamericanos como potencial freno a la influencia de la Revolución Cubana en el continente-, la que junto con los respaldos entregados al proceso por la Iglesia católica chilena y los partidos progresistas se constituyeron en los principales factores que aportaron urgencia y viabilidad al proceso reformista en el país. La Reforma Agraria se inicia en el gobierno de don Jorge Alessandri Rodríguez (1958-1964) con la dictación de la Ley $\mathrm{N}^{\circ} 15.020$ del 27.11.1962, conocida como "la reforma del macetero" debido a las dificultades operativas en financiamiento y expropiación que representaba su implementación, siendo su aplicación marginal en el inicio del proceso reformista chileno, ya que durante su vigencia se expropiaron un total de 17 grandes propiedades, que representaban solo 142.000 hectáreas de toda la tierra agrícola nacional (Ortega, 1987, p. 32).

El proceso de cambio estructural agrario recibió su mayor impulso en el gobierno de Eduardo Frei Montalva (1964-1970), a partir de la dictación en el año 1967 de dos articulados que en forma convergente aportaron significativamente al proceso reformista. Ese año se dictan la Ley № 16.625 de sindicalización campesina, que reconoció este derecho social a inquilinos, afuerinos, voluntarios y minifundistas y consolidó la organización en el medio rural como principal base del proceso reformista; y la Ley $\mathrm{N}^{\circ} 16.640$ de Reforma Agraria que agiliza la aplicación legal para la expropiación y para la implementación de asentamientos campesinos en los predios reformados (Armijo y Caviedes, 1997, pp. 7-11).

La Ley de Reforma Agraria de 1967 fue precedida por reformas constitucionales respecto de la función social de la propiedad en los siguientes términos:

La función social de la propiedad comprende cuanto exijan los intereses generales del Estado, la utilidad y salubridad públicas, el mejor aprovechamiento de las fuentes y energías productivas en el servicio de la colectividad y la elevación de las condiciones de vida del común de los habitantes. Cuando el interés de la comunidad nacional lo exijan, la ley podrá reservar al Estado el dominio exclusivo de recursos naturales, bienes de producción u otros, que declare de importancia preeminente para la vida económica, social o cultural del país (Art. Único, Ley 16.615 del 18.1.1967). 
Estas disposiciones permitieron agilizar el proceso expropiatorio, estableciendo además que el cuerpo legal

(...) determinará las normas para fijar la indemnización, el tribunal que conozca de las reclamaciones sobre su monto, el que en todo caso fallará conforme a derecho, la forma de extinguir esta obligación, y las oportunidades y modo en que el expropiador tomará posesión material del bien expropiado. Cuando se trate de expropiación de predios rústicos, la indemnización será equivalente al avalúo vigente para los efectos de la contribución territorial, más el valor de las mejoras que no estuvieren comprendidas en dicho avalúo, y podrá pagarse con una parte al contado y el saldo en cuotas en un plazo no superior a treinta años todo ello en la forma y condiciones que la ley determine. (...) La pequeña propiedad rústica trabajada por su dueño y la vivienda habitada por su propietario no podrán ser expropiadas sin previo pago de indemnización (Art. Único Ley 16.615 del 18.1.1967).

Las responsabilidades técnicas y administrativas del proceso estaban principalmente a cargo de la Corporación de Reforma Agraria (CORA), cuyos objetivos definidos en la Ley estaban orientados al mejoramiento de la calidad de vida de la población campesina de acuerdo con las necesidades sociales y económicas del país o de cada región en particular, mediante el acceso de la propiedad de la tierra a los campesinos que la trabajaban; a la incorporación de nuevas tierras del Estado, de instituciones públicas o de particulares a la producción, para su posterior entrega en propiedad a campesinos y cooperativas en copropiedad; y a proporcionar asistencia técnica y crediticia a los asignatarios, asentados y cooperativas de Reforma Agraria. Asimismo, se creó el Instituto de Desarrollo Agropecuario (INDAP), que tenía como objetivos brindar asistencia técnica gratuita y ayuda crediticia a pequeños y medianos agricultores (Art. №12, Ley 15.020 del 15.11.1962).

La unidad de medida de la tierra para expropiación, reserva y asignación fue definida en el Artículo № 16 de la Ley № 16.640 como Hectárea de Riego Básico (HRB), medida que permitía establecer las equivalencias del potencial productivo entre suelos de diferentes calidades y ubicaciones, tomando como referente la capacidad de producción de una hectárea física del Valle del Maipo, considerada como la mejor tierra agrícola del país en aquellos años. La expropiación de los predios se aplicaba sobre las $80 \mathrm{HRB}$, permitiendo al propietario conservar bajo su dominio una reserva que no superara dicha medida. Una vez sucedida la expropiación, la CORA tomaba posesión del predio, organizando su producción en una figura colectiva denominada asentamiento, la que podía durar entre tres y cinco años. El asentamiento era una modalidad que consistía en sociedades de campesinos, las que en conjunto con el Estado representado por la CORA explotaban un predio como etapa previa a la asignación de tierras, con el fin de desarrollar el trabajo 
cooperativo y la capacidad técnica y empresarial de los trabajadores agrícolas (Cereceda y Barría, 1984, p. 62). Pasado el plazo de los 5 años, los beneficiados decidían si se mantenía la modalidad colectiva a través de cooperativas; si se asignaban de manera individual en unidades económicas familiares o se realizaba la asignación en modalidad mixta en que se contaba con unidades productivas en parte familiares (la casa y el huerto) y en parte cooperativas (las tierras de producción). Durante el período 1964-1970 se estima que se expropiaron unos 1.400 predios con una extensión aproximada de 3.000 .000 de hectáreas, beneficiando a un total aproximado de 30.000 familias asignadas en régimen de asentamiento (CORA, 1970, p. 45; Cereceda y Barría, 1984, p. 62).

En el gobierno de Salvador Allende Gossens (1970-1973) se aceleró el proceso reformista de expropiación de predios, a través de ocupaciones de hecho realizadas por organizaciones campesinas y que fueron conocidas como "tomas de fundo", las que presionaban por una rápida entrega del predio y por la pronta regularización de la ocupación través de la toma de posesión por parte de la CORA, conforme a la legislación vigente. Durante el período se estima una expropiación de alrededor de 4.000 predios con un total de 6.800.000 hectáreas (Cereceda y Barría, 1984, p. 63).

El proceso reformista culminó abruptamente a partir del golpe de Estado de septiembre de 1973, dando inicio a un nuevo proceso conocido como Contrarreforma Agraria, que buscó regularizar en forma rápida la tenencia de la tierra agraria y liquidar las tierras expropiadas hasta la fecha. El golpe de Estado dio origen a una dictadura cívico militar que se extendió entre septiembre de 1973 y marzo de 1990, período en que los marcos regulatorios y las acciones estatales de apoyo al campesinado sufrieron una profunda transformación, en el marco de la implementación de un nuevo modelo económico para el país, que introdujo las lógicas de libre mercado en el agro.

\section{La Reforma Agraria, la Contrarreforma Agraria y los Derechos Campesinos}

\section{La Reforma Agraria y la protección de los Derechos Campesinos}

Para la CORA, principal organismo ejecutor de la Reforma Agraria chilena, los derechos campesinos se encontraban definidos en el centro del proceso reformista:

Lo más positivo de lo vivido en el campo chileno, es que la mujer y el hombre campesino, hasta ayer seres olvidados y postergados hoy ocupan su lugar en la 
comunidad nacional. Sus derechos han sido por primera vez reconocidos, su dignidad, respetada (CORA, 1970, p. 10).

Estos derechos declarados en los documentos oficiales del citado organismo correspondían a: acceso a la tierra, acceso a la asistencia técnica, acceso al crédito agrícola preferente y acceso a la comercialización. Asimismo, se reconoce el derecho de asociación sindical de los trabajadores agrícolas, como el más relevante avance en materia social agraria del período. Complementariamente, se consideraban los derechos a la educación, la salud y la vivienda, vinculados a partir de las estrategias de mejora de las condiciones de vida materiales del campesino y su familia, que se impulsaban desde los propios asentamientos campesinos y desde el Estado (CORA, 1970, p. 21).

Con el fin de concretar estas declaraciones y reconocimientos explícitos de derechos campesinos, se aplica entre los años 1962 y 1973 el proceso reformista. El derecho de acceso a la tierra se concreta expropiando en el período un total de 5.809 predios, los que representaban 9.965.900 hectáreas físicas, alcanzando el 40\% del total de la superficie del país en HRB. Estos resultados permiten estimar que se incorporan al proceso de Reforma Agraria un total aproximado de 70 mil familias campesinas a través de asentamientos (Garrido, 1988, p. 81). Una vez expropiada la tierra, se constituían los asentamientos con los trabajadores que vivían allí y que voluntariamente quisieran formar parte de estos, considerando también la situación potencial de campesinos que pertenecieran a otras haciendas reformadas y que por capacidad predial no hubiesen sido asignados en su asentamiento original. Los principales objetivos básicos de los asentamientos campesinos, fijados en el Art. № 66 de la Ley 16.640, eran los siguientes:

1. Explotar eficientemente las tierras que comprende el asentamiento, mejorando la producción mediante la asistencia que proporciona o aporta la Corporación de la Reforma Agraria; 2) Preparar y capacitar a los asentados para que asuman completamente, al término del asentamiento, las responsabilidades de propietarios y empresarios agrícolas; 3) Orientar e impulsar el desarrollo de la comunidad, promoviendo la preparación, creación y fortalecimiento de sus cooperativas u organizaciones de base; 4) Promover la capitalización de los asentados, procurando que el mayor ingreso que obtengan sea destinado principalmente a este objeto; y; 5) Construir la infraestructura mínima necesaria para el desarrollo de la vida familiar y comunitaria de los asentados y futuros asignatarios, así como la infraestructura necesaria para la normal explotación actual y futura del predio. 
Los asentamientos se organizaban bajo la figura de Sociedad Agrícola de Reforma Agraria, concebida como una empresa de autogestión dirigida por un Consejo de Administración integrado hasta por cinco campesinos (CORA, 1970, p. 42). El asentamiento mantenía la estructura de trabajo y el personal del predio, con el fin de atenuar los efectos productivos negativos que pudiera tener el cambio de gestión producida, permitiendo que la mayoría de las decisiones internas de la explotación fueran tomadas por los propios campesinos. La Corporación de Reforma Agraria conservaba las decisiones fundamentales de la empresa campesina con respecto a planificación, inversión, créditos, comercialización y abastecimiento. La estrategia de acompañamiento se basaba en el derecho de acceso a la asistencia técnica, focalizando sus esfuerzos en la formación técnica campesina en los requerimientos propios de la producción agropecuaria, en su calidad de futuros productores agrícolas, preferentemente en las áreas de técnicas agropecuarias, manejo empresarial y capacitación cooperativa (ICIRA, 1970, p. 8), junto con la capitalización en maquinaria agrícola, ganadería, herramientas de trabajo, tecnología e insumos para la producción (CORA, 1970, pp. 86-89).

El derecho al acceso preferente al crédito agrícola para el sector reformado quedó definido en el Art. № 203 de la Ley 16.640, que establecía un "amplio y seguro acceso al crédito de parte de los campesinos asentados", siendo responsabilidad del Consejo Nacional de Crédito Agrícola realizar las medidas pertinentes para implementar este mandato. Asimismo, el INDAP debía aportar con líneas crediticias para pequeños y medianos productores, incluyendo a quienes exploten minifundios, campesinos indígenas, cooperativas, actividades de artesanía y pequeña industria (Art. № 12, Ley 15.020 del 15.11.1962). Específicamente, en el caso de las cooperativas agrícolas, se presentaba un plan de explotación del predio, que era revisado y aprobado por el INDAP, institución que les proporcionaba el crédito correspondiente, permitiendo cancelar salarios y gastos operacionales a la espera de las ganancias de la cosecha, que aportarían los recursos frescos para el funcionamiento productivo y el pago de la deuda (Cereceda y Barría, 1984, p. 75). En el marco de la comercialización, la CORA asumió un rol central, operando a través de los canales tradiciones de comercialización y abastecimiento, logrando algunas economías de escala al concentrar ventas y compras de diferentes predios. La participación directa del sector reformado se sumó complementariamente, a través de la participación en mercados locales (ICIRA, 1970, p. 5).

Con respecto al derecho campesino de asociación sindical, en 1973 existían 870 sindicatos en el país, que convocaban a 229.836 afiliados, con un tamaño promedio de 264 integrantes. Asimismo, existían 328 cooperativas campesinas que contaban con 86.000 socios y un total de 2.100 comités de pequeños agricultores (Ortega, 1987, p. 35; Garrido, 1988, p. 106; Rivera, 1988, p. 209). Las organizaciones 
tuvieron oportunidad de contar con representación campesina en instituciones gubernamentales del sector agrícola, con proyecciones de participación efectiva en políticas sectoriales y centros directivos de los organismos públicos (ICIRA, 1970, p. 13). Asimismo, la ley definía la posibilidad de asignación en modalidad cooperativa, siendo asignadas hasta septiembre de 1973 un total de 1.057.250,25 hectáreas a cooperativas campesinas (Yrarrázabal, 1979, p. 4; Bengoa, 1984, pp. 42-43). Tanto los asentamientos campesinos organizados en Sociedades Agrícolas, como las cooperativas de Reforma Agraria podían asociarse en Cooperativas Regionales, con el fin de realizar acciones conjuntas y beneficiarse con economías de escala (CORA, 1970, p. 51).

Los derechos campesinos en las áreas de educación, salud y vivienda, se expresaron en mejoras en las condiciones materiales de vida a través de acciones de carácter social que apoyaron el proceso productivo reformador. Así, entonces, para concretar el derecho campesino a la educación se consideró la información aportada por el Censo de Población y Vivienda del año 1960, que arrojaba cifras de analfabetismo de la población total de 16,4\% y de analfabetismo rural de 33,6\% en la población mayor de 15 años. Como respuesta a esta realidad, se organizó en el país una Reforma Educativa que expandió sustancialmente el acceso a la educación formal, modificó los programas de estudio, aumentó la enseñanza obligatoria básica de 6 a 8 años y redefinió la enseñanza secundaria en 4 años. En ese marco, la educación de adultos fue impulsada a través de programas de alfabetización campesina y de regularización de enseñanza básica rural, apoyada en la concepción pedagógica del educador brasileño Paulo Freire, utilizando preferentemente el método de la palabra generadora y destacando a la base del proceso formativo, conceptos tales: como casa, pala, camino, sindicato, compañero, yugo, trabajo y pueblo (Pinto, 2004, p. 249). Esta acción alfabetizadora fue considerada la "primera herramienta para su participación activa en la vida nacional" (CORA, 1970, p. 55) y "la base fundamental de conocimientos para comprender y transformar el medio en el cuál debe desarrollarse" (ICIRA, 1970, p. 8).

Con respecto al derecho campesino a la vivienda, CORA $(1970$, p. 96) definía la vivienda rural en una forma integrada, como "la habitación campesina, los espacios intermedios y de circulación, construcciones adyacentes de trabajo agropecuario, crianza casera y huerto familiar" y aportaba a la construcción de viviendas campesinas desde estos estándares. Asimismo, estableció una caracterización para los villorrios agrícolas, a través de una zonificación interna que considera las zonas de mayor protección para la construcción de viviendas, servicios básicos, equipamiento comunitario, áreas verdes, áreas deportivas, equipamiento agrícola, calles internas y caminos de acceso, cautelando su cumplimiento en las inversiones realizadas. El tamaño promedio destinado a los sitios para las viviendas se fijó en no 
menos a $2.600 \mathrm{~m}^{2}$ ni mayor a $5.000 \mathrm{~m}^{2}$. Las modalidades de inversión en vivienda y equipamiento consideraron la construcción de nuevas unidades o servicios, y la reparación de los existentes hasta la fecha de la expropiación.

En el ámbito del derecho campesino a la salud, las acciones de la Reforma Agraria se coordinaron con las políticas sanitarias chilenas, que en el año 1952, con la creación del Servicio Nacional de Salud, impulsaron servicios gratuitos de medicina preventiva, política nacional de planificación familiar, control pre y posnatal, atención hospitalaria del parto, estimulación de lactancia materna y control de salud en lactantes y preescolares y cobertura universal de vacunaciones y alimentación complementaria. Se buscaba generar una red de salud integrada y de complejidad creciente constituida por postas rurales, atención primaria y hospitalaria para extender la acción sanitaria a toda la población (Goic, 2015, p. 778). La legislación vigente permitía a los organismos de salud aportar con ayuda técnica, financiera o de recursos a instituciones creadas y mantenidas por la comunidad para realizar acciones de salud, por lo que en ocasiones las propias organizaciones campesinas contribuyeron a concretar proyectos de atención sanitaria en zonas rurales desprovistas de dichos servicios, aportando directamente a mejorar la atención primaria de salud, en especial en sus condiciones de acceso, cobertura y oportunidad de atención (Ugarte, 1970, p. 32).

Así, entonces, la declaración del derecho campesino de organización sindical y el derecho de poseer la tierra a quienes la trabajan fueron asumidos explícitamente por los organismos estatales y concretizados a través de una reforma constitucional y de cuerpos legales que formalizaron el proceso y le dieron viabilidad como política del Estado; se crearon organismos públicos especialmente definidos para apoyar la labor agraria; se realizaron aportes de recursos públicos declarados en el presupuesto nacional; $y$, se impulsaron acciones intersectoriales destinadas a este importante grupo social, en el marco de una Reforma Agraria que fue apoyada por amplios sectores de la vida nacional.

\section{La Contrarreforma Agraria y la vulneración de los Derechos Campesinos}

Se estima que en el período 1962-1973 fueron expropiados en el país un total aproximado de 5.500 predios, con un total cercano a 9.600 .000 hectáreas. En el momento del golpe militar de septiembre de 1973, se encontraban asignadas a familias campesinas un total de 1.057.250,25 de hectáreas, restando a esa fecha un saldo de 8.253.596,81 hectáreas no asignadas en poder del Estado (Yrarrázabal, 1979, p. 4; Bengoa, 1984, pp. 42-43). Inmediatamente asumidas las nuevas autoridades militares, se inició una intensa represión masiva, generalizada y sistemática en las 
organizaciones y asentamientos campesinos, orientada en especial a la dirigencia política y sindical. Según los antecedentes recopilados por la Vicaría de la Solidaridad (Daire, 1992, p. 5), en el sector rural chileno cientos de trabajadores rurales pertenecientes a organizaciones campesinas y sindicatos de antiguos latifundios, fueron detenidos en los días posteriores al golpe de Estado por patrullas militares o civiles armados, siendo torturados o ejecutados en forma sumaria. Actualmente aún existen personas que permanecen en calidad de detenidas-desaparecidas a partir de la fecha de su detención. Asimismo, funcionarios de las reparticiones públicas ligadas a la Reforma Agraria fueron acusados de fomentar el activismo político en el campo y fueron víctimas de acciones de represión por parte de las autoridades golpistas. Los operativos militares, allanamientos, arrestos arbitrarios y amedrentamientos en los predios reformados fueron una constante en los primeros años de instauración de la dictadura. Muchos de los valiosos archivos, registros y materiales de trabajo del proceso de Reforma Agraria fueron destruidos como estrategia de protección anticipatoria aplicada por los propios funcionarios del agro con respecto a la información social o política sensible que se poseía de los asentamientos o por destrucción militar directa. Todos aquellos antecedentes que permanecieron, se constituyeron en bases de información que permitieron organizar las asignaciones de tierra y respaldaron la toma de decisiones técnicas de parcelación; junto con confirmar la identificación de los dirigentes campesinos con fines represivos o aportar en los años posteriores los datos de respaldo para su eliminación de las listas de beneficiados.

La primera medida destinada al agro posterior al golpe militar de septiembre de 1973 fue la suspensión en forma inmediata y definitiva de la expropiación de predios. A pesar de que en un principio el nuevo gobierno autoritario no derogó la Ley № 16.640 de Reforma Agraria vigente y dictó complementariamente nuevas normas:

Las tierras expropiadas por la CORA están fundamentalmente destinadas a ser transferidas a los trabajadores agrícolas que acrediten el cumplimiento de requisitos que los habiliten para asumir su responsabilidad de agricultores y que garanticen el mejor aprovechamiento de la capacidad productiva agrícola del país. (Decreto Ley № 1.600 ).

Se inició una progresiva reorientación estructural del modelo económico nacional -que abandonó su rol vigente de Estado centralizado y protector, girando hacia un modelo de libre mercado, donde el rol económico predominante lo ejerce la iniciativa privada y el juego de la libre competencia-adoptando decisiones para el sector rural que impactaron negativamente el área reformada, dado que la principal finalidad de la nueva política agraria fue formar y fortalecer un sector empresarial eficiente que se orientara por una racionalidad económica de maximización de 
beneficios. Es decir, se impulsó un desarrollo capitalista en el agro que se tradujo en las siguientes medidas: liberalización de los precios agrícolas; apertura al mercado internacional; traspaso al sector privado de la asistencia técnica y crediticia; desmovilización de la organización sindical; traspaso de los activos agroindustriales del sector reformado y estatal al sector empresarial; privatización de la actividad forestal; liberalización del mercado de la tierra a través de la disminución de la superficie mínima requerida para la propiedad agrícola rural y del saneamiento de los títulos de dominio de pequeños propietarios y comuneros; y privatización de la tierra agraria controlada por el Estado. A lo anterior se suman la derogación de la prohibición de enajenar tierras asignadas a parceleros de la Reforma Agraria y la autorización para que propietarios individuales entregaran en mediaría o arrendamiento las tierras asignadas por CORA (Cereceda y Barría, 1984, pp. 62-64).

Se da inicio así al proceso de Contrarreforma Agraria, que se realizó a través de cuatro procesos complementarios que corresponden a revocación, asignación a beneficiarios campesinos, asignación a privados y asignación a instituciones públicas (Bellisario, 2013, p. 175). El primer proceso corresponde al mecanismo de revocaciones que reconocía a los propietarios originales los derechos de reserva y exclusiones por razones administrativas o por ocupación por fuerza del predio ("tomas de fundo"). Esta causal permitió restituir en forma parcial o total el 34\% de las tierras expropiadas a los propietarios originales en forma de haciendas indivisas o reservas, estimándose en una superficie aproximada de 3.200.000 hectáreas. El segundo proceso de asignación a beneficiarios campesinos de la Reforma Agraria abarcó un total aproximado de 3.900.000 hectáreas, a través de cooperativas, proyectos de parcelación y venta directa, lo que representa un $41 \%$ de las tierras expropiadas, beneficiando a unas 45.000 familias campesinas a través de parcelaciones.

Debe señalarse que el Artículo № 71 de la Ley 16.640 establecía como requisitos esenciales para ser asignatario de tierras: ser chileno o extranjero con aprobación del Consejo de la CORA; ser campesino; ser mayor de 18 años; poseer aptitudes para el trabajo de campo; no ser propietario de tierras o serlo de una superficie inferior a la unidad agrícola familiar y ser casado o subvenir permanentemente a las necesidades de una familia como jefe de esta. Estos requisitos fueron modificados por los Decretos Ley 208 del año 1973 y 1.600 del año 1976, los que definieron como nuevos antecedentes: no haber sido condenado o encargado reo por sentencia ejecutoriada por delito que merezca una pena de presidio mayor en cualquiera de sus grados; no haber ocupado con violencia el predio ("tomas de fundo") o inducido a otros; ser asentado al momento de la distribución de la tierra o haber estado trabajando en algún predio expropiado por la Corporación; y no haber sido asentado en algún predio revocado. 
Asimismo, la Ley de Reforma Agraria del año 1967 definía en su Artículo 1ํㅡㄴ como campesino

El obrero o empleado cuyo trabajo habitual y continuo se realiza en el campo, así como el ocupante, mediero, arrendatario, tenedor o dueño de tierras, siempre que lo sean respecto de una superficie no superior a la de una unidad agrícola familiar; y en ningún caso se considerará como campesino a la persona que estuviese en posesión de un título profesional universitario (Art. № 1, letra i), Ley de Reforma Agraria № 16.640).

Las modificaciones de los requisitos de asignación señaladas obviaron esta definición, permitiendo asignar tierras a profesionales universitarios, cuyos años de estudios fueron ponderados favorablemente en la postulación por sobre los niveles de analfabetismo y escolaridad básica que caracterizaban a los campesinos que aspiraban a la asignación de tierras. Esta situación benefició con asignación de tierras a personal de administración de fundos, profesionales del agro, burocracia estatal y comerciantes, en un total estimado de 6.000 personas (Bellisario, 2013, p. 175).

Según estimaciones de Ortega (1987, pp. 39-40) del total de 94.194 campesinos adscritos a unidades reformadas, 25.349 pertenecen a predios en que fue revocada su expropiación, 5.000 fueron eliminados de su postulación como resultados de la aplicación de las inhabilidades contenidas en los DL № 208 y DL № 1.600; y un total de 19.920 no alcanzaron el puntaje suficiente para asignación, lo que arroja un saldo final de 43.917 campesinos beneficiados y 50.277 campesinos incorporados inicialmente al proceso de Reforma Agraria por el Estado que no fueron asignatarios de tierras. Sumados a sus cargas familiares, se estima un universo de 253.195 personas excluidas.

El tercer proceso corresponde a la licitación a través de la CORA de las tierras que correspondían mayormente a zonas costeras secas o las estribaciones de las montañas con potencial para silvicultura. Los destinos de estas superficies, que se estiman en 1.600 .000 hectáreas y que corresponden al 16\% del total de tierras expropiadas, fueron asignados a privados por subasta pública o venta directa. El cuarto proceso mantuvo inicialmente un remanente de tierras expropiadas estimadas en unas 900.000 hectáreas bajo la administración del Estado, lo que correspondía al 9\% del total de las tierras expropiadas. Estas tierras de remanente fueron igualmente asignadas, licitadas o rematadas en años posteriores por medianos y grandes empresarios agrícolas vinculados a complejos agroindustriales, agroforestales y grupos económicos del sector (Bengoa, 1984, pp. 42-43). 
Las asignaciones de parcelas se regían por tres cuerpos legales diferentes. Las asignaciones que se habían realizado hasta 1973, se habían guiado por las condiciones establecidas por la propia Ley № 16.640 , diseñada para ajustar los pagos a las dinámicas productivas campesinas. El pago de las parcelas asignadas entre 1973 y 1975, las que se estiman en unas 20.000 unidades agrícolas familiares se rigieron por el Decreto Ley № 208, que fijaba dos años de gracia para luego proceder al pago de las cuotas, equivalentes al precio de una cantidad determinada de trigo o maíz, sin pago de intereses y por un período no mayor de 30 años. Las parcelas asignadas después de 1975 , que alcanzan a 17.500 predios, se reglamentan en sus pagos por disposiciones del Decreto Ley № 1.272 y tenían dos años de gracia. Debían cancelar, además, un interés legal anual, que rige aun en los años de gracia. En este último sistema de pago, las cuotas finales corresponden casi al triple del valor de los asignatarios adscritos a la modalidad de la Ley № 16.640 . El atraso de cuotas representaba un cobro de $20,5 \%$ de interés anual sobre lo adeudado (GIA, 1979, pp. 42-43).

En 1980 se derogó el estatuto de protección de las tierras asignadas por la Reforma Agraria, que prohibía su enajenación por 15 años. En atención a las desventajosas condiciones en que la tierra reformada había sido asignada a las familias campesinas, esta medida se tradujo en una explosiva venta de predios entre los años 1980 y 1981, que alcanzó un 53,27\% del total de las parcelas asignadas, y que se deduce que fue motivada por los altos niveles de endeudamiento de cuotas de pago anual y contribuciones que habían acumulado las tierras asignadas y por una permanente ausencia de apoyo estatal a la producción agrícola (Portilla, 2000, pp. 11-12).

Los derechos campesinos garantizados en el período anterior fueron poco a poco vulnerados. El derecho a la tierra se ejerció en forma parcial e incluyó a solo una parte de la población campesina como posible beneficiaria, excluyendo a una importante proporción de las familias originalmente consideradas en los asentamientos. La asignación de tierras se realizó sin asistencia técnica estatal ni acceso preferente al crédito agrícola. La entrega individual los atomizó, restándoles capacidad de negociación frente a los circuitos financieros y de comercialización (GIA, 1979, pp. 42-43). Las organizaciones campesinas fueron progresivamente inmovilizadas, a partir de la persecución política y las acciones de represión ejercidas a sus dirigentes y asociados. Asimismo, se abandonaron las acciones destinadas a garantizar derechos sociales a través de mejoras específicas en las condiciones materiales de vida campesina y que habían sido priorizadas en el período anterior en torno a las áreas de educación, vivienda y salud. Conforme a las nuevas orientaciones de las políticas sociales, el Estado asumió un rol subsidiario y focalizó recursos públicos limitados desde criterios universales de pobreza y vulnerabilidad, invisibilizando las necesidades particulares del sector rural, obligándolo en la práctica a competir 
por el acceso a las escasas asignaciones y beneficios sociales disponibles junto a los sectores urbanos de menores ingresos (Ffrench-Davis y Stallings, 2001, p. 37).

La Corporación de Reforma Agraria, considerado el organismo garante de los derechos campesinos, ejerció funciones durante 16 años, terminando su existencia legal el 31 de diciembre de 1978. Fue reemplazada durante un año por la Oficina de Normalización Agraria, organismo que puso formalmente término a los asuntos pendientes de la CORA en diciembre de 1979 (Garrido, 1988, pp. 223-224). La Ley № 16.640 de Reforma Agraria fue derogada en enero de 1989. El Servicio de Tesorerías continuó emitiendo los Bonos de la Reforma Agraria que fueron necesarios para pagar las indemnizaciones que se encontraran pendientes por las expropiaciones efectuadas en virtud de las Leyes № 15.020 y № 16.640 , conforme a las disposiciones contenidas en la última norma legal, las que mantuvieron su vigencia solo para el efecto del pago pendiente. El derecho al pago de los hacendados por concepto de la expropiación fue garantizado.

\section{Conclusiones}

Al conmemorar 50 años de la dictación de la Ley № 16.640 que respaldó la Reforma Agraria chilena en términos de aplicación efectiva, la revisión en perspectiva histórica de los principales hitos que la constituyeron permite apreciar un proceso que se inicia como respuesta a la creciente preocupación nacional respecto del rol que le corresponde asumir al sector agrario en el desarrollo del país y cuyo desenlace esperado de nuevas oportunidades productivas y sociales para amplios sectores campesinos, se trunca y se redefine a partir de los acontecimientos políticos, sociales y económicos que se suceden en Chile a partir de septiembre de 1973.

En su origen, la Reforma Agraria es concebida como una acción redistributiva de los derechos de propiedad de los recursos naturales, que se encontraban en una situación histórica de alta concentración y de acceso inequitativo de la población campesina a los beneficios derivados de la tenencia de la tierra. En ese principio, el Estado asumió un rol de intervención directa e implementó a través de su institucionalidad las acciones orientadas a modificar estructuralmente la propiedad agraria y potenciar la modernización capitalista del sector, ubicando en el centro del proceso y como destinatario preferente a los derechos del campesinado. Como resultado estructural de la tenencia de la tierra del proceso reformista, desaparece el sistema de la hacienda nacional y como contrapunto, se amplía la pequeña propiedad campesina y emerge la mediana propiedad comercial agroexportadora (Rivera, 1988, p. 81). 
La secuencia reformista fue definida a través de las fases de expropiación; conformación de asentamientos campesinos con apoyo técnico, crediticio y comercial del Estado, a través de la CORA y el INDAP; y asignación de tierras a las familias campesinas en modalidades individual, cooperativa o mixta. La etapa de expropiación tenía sus propios plazos a partir de las formalidades burocráticas que representaba la recepción del predio por parte de la CORA, los acuerdos con la parte propietaria con respecto al valor de la propiedad para efectos de expropiación y selección de la reserva, y la toma de posesión definitiva del predio por parte de la Corporación. La etapa siguiente, correspondiente al asentamiento campesino, proyectaba un promedio de tres a cinco años, tiempo estimado en el desarrollo de una relativa autonomía campesina en relación con el manejo productivo de su predio, siendo posible extender su funcionamiento a petición de los propios asentados o por sugerencia de la CORA, tomando como referente el avance efectivo de los objetivos planteados en torno a producción, organización y autogestión. Todos los procesos anteriores desplazaban la etapa de asignación para los años posteriores, superando en muchas ocasiones el plazo legal estipulado originalmente.

Por ello, el traumático cambio político del país a partir del año 1973 encontró al proceso con aproximadamente el $90 \%$ de la tierra reformada bajo dependencia directa del Estado y, por consiguiente, las decisiones que asumieron las nuevas autoridades militares en la asignación de tierras impactaron en forma central el futuro desarrollo agrario nacional, alineándolo en forma diligente a las nuevas lógicas de un modelo económico de libre mercado, que requería para su funcionamiento la creación de un mercado abierto de tierras, base de un capitalismo agrario orientado a la exportación a través de la agroindustria. En este nuevo diseño, el campesinado asignatario fue desplazado bruscamente de su protagonismo como sujeto de derechos garantizados por el Estado y como beneficiario central de la Reforma Agraria.

En estas nuevas condiciones, la población campesina asignataria despojada de sus derechos debió enfrentarse en forma autónoma, sin apoyo estatal ni social a las nuevas reglas del mercado. Cuando la experiencia como parcelero asignatario fue exitosa, el sistema le permitió insertarse en los procesos capitalistas agrarios, mediante un rol secundario de proveedor de recursos naturales, insumos y servicios en las cadenas de producción agroindustriales. Por el contrario, cuando la experiencia como parcelero asignatario fue adversa o no recibió los beneficios esperados, sufrió la pérdida de su tierra y de su patrimonio, siendo su inserción al proceso capitalista agrario en calidad de proveedor de mano de obra asalariada en condiciones de precariedad laboral y económica, pasando a formar parte de villorrios rurales o sectores de pobreza urbana que fueron incorporados a los circuitos claves de reclutamiento de mano de obra temporal en faenas agrícolas 
o forestales. El campesinado ha quedado relegado a un rol de mero testigo de un desarrollo agrario destinado inicialmente a cautelar su derecho de poseer la tierra que trabajaba, y que terminó integrándole desde un proceso productivo capitalista que se la arrebató, la incorporó a su propio concepto y diseño de desarrollo agrario y la utilizó para explotar los recursos naturales disponibles y transarlos en el mercado global. Antes de la Reforma Agraria trabajó como inquilino para el hacendado. Después de la Contrarreforma Agraria trabaja como asalariado para el empresariado.

\section{Referencias}

Alaluf, D., Robles, E. y López A.M. (1969). Cambios ocurridos en la agricultura chilena en el período comprendido entre los censos agropecuarios 1955 y 1965. Santiago: ICIRA.

Armijo, G. y Caviedes, B. (1997). Vicisitudes y Cambios en el Mundo Rural Chileno. La última modernización agraria. ¿La gran solución de fin de siglo?. Anales de la Universidad de Chile, Sexta Serie № 5. doi:10.5354/0717-8883.1997.2984

Bellisario, A. (2013). La Reforma Agraria chilena. Reformismo, socialismo y Neoliberalismo, 1964-1980. Historia Agraria № 59, 159-190. Sociedad Española de Historia Agraria. Recuperado de: http://historiaagraria.com/info_articulo.php?id=626.

Bengoa, J. (1984). El campesinado chileno después de la Reforma Agraria. Santiago: Ediciones SUR. Colección Estudios Sociales.

Cereceda, L. y Barría, L. (1984). Comportamiento económico y racionalidad del campesino. Instituto Chileno de Educación Cooperativa. Santiago: ICECOOP.

CORA (1970). Reforma Agraria Chilena 1965-1970. Santiago: Corporación de la Reforma Agraria. Ministerio de Agricultura.

Daire, A. (1992). El proceso represivo. Documento de Trabajo. Santiago de Chile: Vicaría de la Solidaridad. Recuperado de: http://www.archivovicaria.cl/archivos/VS4b4ca19daa347_12012010_121pm.pdf.

Ffrench-Davis, R. y Stallings, B. (2001). Reformas, Crecimiento y Políticas Sociales en Chile desde 1973. Santiago de Chile: LOM.

Garrido, J. (ed.) (1988). Historia de la Reforma Agraria en Chile. Santiago de Chile: Editorial Universitaria.

GIA (1979). Los parceleros de la Reforma Agraria. Santiago de Chile: Grupo de Investigaciones Agrarias. Academia de Humanismo Cristiano. 
Goic, A. (2015). El sistema de salud en Chile. Una tarea pendiente. Revista Médica de Chile, 143, 774-786. Recuperado de http://www.scielo.cl/pdf/rmc/v143n6/art11.pdf/ http://dx.doi. org/10.4067/S0034-98872015000600011

ICIRA (1970). Síntesis de algunos aspectos de la Reforma Agraria chilena 1964-1969. Documento interno. Mimeo.

Ortega, E. (1987). Transformaciones agrarias y campesinado. De la participación a la exclusión. Corporación de Investigaciones Económicas para Latinoamérica. Santiago de Chile: CIEPLAN.

Pinto, R. (2004). Paulo Freire. Un educador humanista cristiano en Chile. Revista Pensamiento Educativo. Vol. 34, 234-258. Facultad de Educación. Pontificia Universidad Católica de Chile. Vol. 34, 234-258. Recuperado de http://pensamientoeducativo.uc.cl/files/journals/2/ articles/286/public/286-650-1-PB.pdf

Portilla, B. (2000). La política agrícola en Chile. Lecciones de tres décadas. Santiago de Chile: CEPAL.

República de Chile (1962). Ley de Reforma Agraria № 15.020. Ministerio de Agricultura. Recuperado de https://www.leychile.cl/Navegar?idNorma=28016

República de Chile (1967). Ley № 16.615. Modifica la Constitución Política del Estado № 16.625. Ministerio de Justicia. Recuperado de https://www.leychile.cl/ Navegar?idNorma $=130884$

República de Chile (1967). Ley de Régimen Sindical en la Agricultura № 16.625. Ministerio del Trabajo y Previsión Social. Recuperado de https://www.leychile.cl/Navegar?idNorma=28586

República de Chile (1967). Ley de Reforma Agraria № 16.640. Ministerio de Agricultura. Recuperado de http://www.leychile.cl/Navegar?idNorma=28596\&r=1

República de Chile (1974). Decreto Ley № 208. Modifica la Ley № 16.640 de Reforma Agraria y declara inexpropiables los predios que se encuentran en la situación que indica. Ministerio de Agricultura. Recuperado de https://www.leychile.cl/Navegar?idNorma=5866

República de Chile (1975). Decreto Ley № 1.272. Modifica disposiciones de la Ley № 16.640. Recuperado de https://www.leychile.cl/Navegar?idNorma=6543

República de Chile (1976). Decreto Ley № 1.600 sobre Reforma Agraria y Establece Normas sobre enajenación de tierras asignadas. Ministerio de Agricultura. Recuperado de https:// www.leychile.cl/Navegar?idNorma $=6677$

Rivera, R. (1988). Los campesinos chilenos. Santiago de Chile: Grupo de Investigaciones Agrarias. Academia de Humanismo Cristiano. 
Suárez, M. (1972). Las empresas comunitarias campesinas en Chile. Instituto Interamericano de Ciencias Agrícolas de la Organización de Estados Americanos. Bogotá: Centro Interamericano de Desarrollo Rural y Reforma Agraria.

Ugarte, J. (1970) Salud y Comunidad. Cuadernos Médico Sociales. № 3, pp. 31-32. Recuperado de http://cms.colegiomedico.cl/Magazine/1970/11/3/11_3_8.pdf

Yrarrázabal, R. (1979). Reforma Agraria en Chile. Revista Ciencia e Investigación Agraria. Escuela de Agronomía. Vol. 6. №1, Enero-Marzo. pp. 3-14. Pontificia Universidad Católica de Chile. http://dx.doi.org/10.7764/rcia.v6i1.597

Recibido: $27 / 7 / 2017$

Aceptado: 31/10/2017 